\title{
Board Committees, CEO Compensation, and
}

\section{Earnings Management*}

\author{
Christian Laux† Volker Laux
}

September 2006

*We thank Harry Evans, Roman Inderst, Bill Kinney, Christian Leuz, Paul Newman, Jason Schloetzer and workshop participants at the London School of Economics, University of Bern, University of Frankfurt, University of Lausanne, University of Mainz, University of Texas at Austin, and the 2006 EIASM Workshop of Accounting and Economics for their helpful comments.

${ }^{\dagger}$ Goethe University Frankfurt, Finance Department, and CFS, laux@finance.uni-frankfurt.de.

$\ddagger$ University of Texas at Austin, Department of Accounting, volker.laux@mccombs.utexas.edu. 


\begin{abstract}
We analyze the effect of committee formation on how corporate boards perform two main functions: setting CEO pay and overseeing the financial reporting process. The use of performance-based pay schemes induces the CEO to manipulate earnings, which leads to an increased need for board oversight. If the whole board is responsible for both functions, it is inclined to provide the $\mathrm{CEO}$ with a compensation scheme that is relatively insensitive to performance in order to reduce the burden of subsequent monitoring. When the functions are separated through the formation of committees, the compensation committee is willing to choose a higher pay-performance sensitivity as the increased cost of oversight is borne by the audit committee. Our model generates predictions relating the board committee structure to the pay-performance sensitivity of CEO compensation, the quality of board oversight, and the level of earnings management.

JEL classifications: D23, D73, G34, K22, L29

Keywords: Corporate Governance, Executive Compensation, Earnings Management, Board Oversight
\end{abstract}

\title{
1 Introduction
}

There is a widespread concern that the surge in CEO pay and recent spectacular cases of accounting fraud reflect a failure of corporate governance. This concern prompted the enactment of the Sarbanes-Oxley Act of 2002 and is also reflected in a much discussed book by Bebchuk and Fried (2004). Special attention in the discussion has been devoted to the role of the boards of directors. Until recently little was known about the effect of board structure on corporate performance. However, a 
large empirical and theoretical literature has now emerged to shed some light on this interaction. Much of this literature focuses on board independence and analyzes how it affects CEO compensation, CEO turnover, monitoring, and oversight of the accounting process (see Hermalin and Weisbach (2003) for an overview). One reason is certainly that board independence is very much at the centre of the public discussion.

In contrast, the role of delegating board functions to committees has received hardly any attention in the academic literature, though most board functions are performed by committees. As a director interviewed by Lorsch and MacIver (1989) remarked: "The work of the board is done in committees." (See Adams (2003) for further discussion.)

One potential advantage of delegating board functions to smaller subgroups of the board is that this can reduce the free-rider problem that plagues large groups. We point out a more subtle effect. When different groups perform different functions, the implied separation of board functions affects decision-making on the board. This in turn has important implications for corporate governance.

To sketch the idea, consider a CEO who is hired to work on a productive task. To provide the CEO with incentives to work hard, the board links CEO pay to a performance measure. However, the performance measure is imperfect in the sense that it can be manipulated at the expense of long-term shareholder value. The compensation scheme therefore not only motivates the CEO to work hard on the productive task, but also encourages him to engage in manipulative actions. Such actions may include accrual management or real earnings management such as reducing R\&D expenses. We refer to both types of activities as earnings management.

The board of directors has to perform the two functions of setting CEO pay and overseeing the financial reporting process (monitoring). Monitoring is privately costly 
for directors but helps to curb earnings management. If the two functions are allocated to the same group of directors, they will take into account that linking CEO pay closely to performance increases the CEO's incentive to engage in manipulation and hence puts them under greater pressure to perform their oversight duty. Directors will therefore lower the pay-performance sensitivity of CEO compensation in order to reduce the need for monitoring. When committees are formed, functions are separated, and the compensation committee will be responsible for setting CEO pay while the audit committee will perform the oversight function. In such a case, the compensation committee is much more willing to drive up the pay-performance sensitivity of CEO compensation because it does not need to bear the cost of subsequent monitoring. The increase in the pay-performance sensitivity that results from a separation of functions not only influences the behavior of the CEO but also the quality of board oversight. Once the CEO faces strong incentives to engage in earnings management, the audit committee will find it optimal to be more diligent in overseeing the financial reporting process.

The formation of committees per se does not guarantee a clean separation of functions. After all, board members may sit on more than one committee, as well as meet in general meetings. For this reason, task separation on boards not only depends on the presence of committees, but on the degree of interaction between these committees. We refer to this interaction as committee interlock. Committee interlock is expected to increase, for example, if the fraction of directors who serve on both committees is larger.

Our model predicts that a reduction in the degree of committee interlock, which increases the level of task separation, results in a stronger pay-performance sensitivity of the CEO's compensation contract. Clearly, a compensation scheme that links 
pay more tightly to performance will increase the CEO's direct incentive to engage in manipulative behavior. However, this does not necessarily lead to an increase in the (expected) level of earnings management as is widely argued by policymakers and regulators. This is because providing the CEO with stronger incentives will also increase the audit committee's attention to overseeing the financial reporting process. Depending on which effect is more powerful, the level of earnings management can increase or decrease in equilibrium. The presence of these two countervailing forces might explain why the recent study by Erickson, Hanlon, and Maydew (2006) finds no clear evidence of a link between the pay-performance sensitivity of executive compensation contracts and the incidence of accounting fraud.

However, a higher pay-performance sensitivity will result in more earnings management if the audit committee's monitoring incentive is relatively low (e.g., due to low stock ownership). But even in this case, linking pay closely to performance is not necessarily undesirable. Shareholders may well accept the increase in earnings management that comes with an increase in the pay-performance sensitivity as greater incentives also induce the CEO to work harder on the productive task.

There is a large and growing empirical literature that analyzes the relation between audit committee or board characteristics such as independence, size, and director background on the one hand and firm performance, CEO compensation, CEO turnover, and earnings management on the other hand (see, e.g., Klein (2002), Farber (2005), Larcker, Richardson, Tuna (2005), and, for a survey, Hermalin and Weisbach (2003)). Our paper contributes to this literature by carving out another channel through which the board structure has an impact: the separation of board functions. Our analysis provides a number of testable predictions relating committee interlock to the pay-performance sensitivity of CEO compensation, earnings management, and 
board oversight.

Theoretical contributions that discuss the effect of the board structure, e.g., by Hermalin and Weisbach (1998), Almazan and Suarez (2003), and Hermalin (2005), have mainly focused on board independence and diligence. Closest to our paper is the work by Adams and Ferreira (forthcoming), who analyze the board's two roles of advising and monitoring the CEO. They show that if both functions are performed by the same group of directors, the CEO is unwilling to reveal information that helps directors to provide advice, as directors can also use the information for monitoring purposes. A separation of functions is beneficial because it serves as a substitute for a commitment not to use the revealed information against the CEO. In contrast, in our setting, the separation of functions changes how the compensation committee accounts for the cost of monitoring when choosing the pay-performance sensitivity of the CEO's compensation contract. With separated responsibilities, the compensation committee is more willing to provide strong incentives to the CEO, which puts the audit committee under greater pressure to diligently perform the oversight task.

The paper proceeds as follows. In the next section we present the model. In section 3 we show how task separation on boards influences the board's decision making and determine the optimal degree of committee interlock. Empirical implications are discussed in section 4 . We conclude in section 5 .

\section{Model}

There are three groups of agents: shareholders, the board of directors, and the CEO. The board of directors has to perform the two functions of setting CEO pay and overseeing the financial reporting process. These functions are delegated to two board 
committees, the compensation committee and the audit committee. When designing the compensation scheme for the CEO, the compensation committee must take into account that the performance measure is manipulable through earnings management. To control earnings management, the compensation committee can either lower the pay-performance sensitivity of the CEO's compensation contract or the audit committee can increase the effort devoted to overseeing the financial reporting process. We analyze how the formation and structure of board committees affects how the board uses these two instruments and their interrelation.

The timing of events is as follows.

Stage 1. The firm is established and shareholders hire a CEO to run the firm. Shareholders also employ a board of directors and decide on how the board is organized. That is, committees are formed and directors are allocated to the different committees. The formation and structure of committees affects the degree of task separation on the board. The extent to which functions are separated is captured by the variable $\gamma$, which is explained in detail later in this section.

Stage 2. The compensation committee sets CEO pay. In general, it has a whole set of alternatives available, e.g., it can use linear or non-linear contracts and choose between different performance measures, including accounting earnings reports and the share price. For the purpose of this paper, these differences are not essential. What matters though is that the performance measure is manipulable, e.g., through accrual management or real earnings management such as reducing $R \& D$ expenses. We use the term earnings management to include both types of activities. Linking pay to the performance measure therefore provides the $\mathrm{CEO}$ with some incentives to engage in earnings management. The connection between earnings management and 
CEO pay is obvious if the bonus is based on the earnings report. In this case, the CEO will have an incentive to manipulate current earnings at the expense of future earnings if he has a shorter time horizon than shareholders (Feltham and Xie (1994), Dutta and Gigler (2002)). When executive pay is based on stock or stock options, the CEO is still able to benefit from earnings manipulations if the market is not fully able to undo these manipulations in pricing the stock (Fischer and Verrecchia (2000), Ewert and Wagenhofer (2005)). Empirical studies provide evidence suggesting that this is generally the case; that is, managers are indeed able to manipulate the stock price to their benefit through earnings management (Sloan (1996), Collins and Hribar (2000)).

We take the performance measure, $M$, as given, and consider linear compensation schemes. CEO pay is $w(M)=F+b M$ and consists of a fixed component $F$ and a variable component $b M$, where $b$ is interpreted as the pay-performance sensitivity of CEO compensation. The compensation committee's task is therefore to set the pay-performance sensitivity $b$ and the fix pay $F$.

Stage 3. The CEO engages in a productive act, $a_{1} \geq 0$, and a manipulative act, $a_{2} \geq 0$. The productive act positively affects both the performance measure and the long-term firm value. In contrast, the manipulative act boosts only the performance measure, possibly at the expense of long-term firm value. The negative effect of $a_{2}$ on firm value may stem from distortions of the firm's operating and investment decisions as well as cost of potential litigation and loss of reputation.

At the same time, the audit committee chooses the monitoring intensity, e. Diligent monitoring by the audit committee makes it more difficult for the CEO to successfully manipulate the performance measure. The monitoring effort $e$ captures the 
time and attention the audit committee devotes to its duties like arranging meetings with management to discuss annual and quarterly financial statements, engaging in vigorous debate, and asking probing questions. We model this by assuming that the "productivity" of the manipulative act $a_{2}$ is a decreasing function of $e$. In other words, higher monitoring reduces the CEO's manipulation ability.

All activities are unobservable. The performance measure and the long-term value of the firm (prior to CEO compensation) are given by

$$
M=m_{1} a_{1}+m(e) a_{2}
$$

and

$$
Y=v_{1} a_{1}-v(e) a_{2}
$$

with $m_{1}>0, v_{1}>0, m(e)>0, v(e) \geq 0, m^{\prime}(e)<0$, and $v^{\prime}(e) \leq 0$. We allow for the possibility that $v(e)$ is zero regardless of $e$ to capture situations where manipulation does not directly affect firm value. However, note that even in this case the manipulative act is still detrimental to shareholders as it leads to excessive CEO compensation. For simplicity we assume in the following that $e \in[0,1], m(e)=m_{2}(1-e)$, and $v(e)=v_{2}(1-e)$, with $m_{2}>0$ and $v_{2} \geq 0$. Thus, monitoring is normalized to take on values between zero and one, where $e=0$ is the lowest level of monitoring. In addition, we assume that the performance measure is more sensitive to the productive act than to the manipulative act $\left(m_{1}>m_{2}\right)$. This assumption assures that the considered optimization problems are concave.

Directors' personal cost of performing the minimum level of oversight, $e=0$, and the personal cost of setting CEO compensation are normalized to zero. Choosing an oversight effort above the minimum level involves a private cost $c(e)$, which is increasing and strictly convex, with $c(0)=0, c^{\prime}(0)=0$, and $\lim _{e \rightarrow 1} c^{\prime}(e)=\infty$. 
The CEO's private cost of undertaking the activity $a_{i}$ is $c\left(a_{i}\right)=0.5 a_{i}^{2}$ for $i=1,2$. $c\left(a_{1}\right)$ is the standard effort cost (or, equivalently, reduced private benefits). The cost of manipulation, $c\left(a_{2}\right)$, may stem from litigation, reputation, or psychic costs. It is worth noting that one could assume that board monitoring not only reduces the productivity of the manipulative act $a_{2}$ but also increases the CEO's cost of manipulation, $c\left(a_{2}\right)$. However, this would merely complicate our exposition without altering the insights of our model.

Preferences and board structure. All agents are risk neutral and the risk-free rate is zero. The CEO has no private wealth and his reservation utility is normalized to zero.

The CEO's expected utility is

$$
U_{C E O}=w(M)-0.5 a_{1}^{2}-0.5 a_{2}^{2}
$$

Shareholders' expected payoff net of CEO compensation, i.e., the value of the firm, is

$$
V=Y-w(M)
$$

To model the preferences of the board, we follow the approach in Hermalin and Weisbach (1998), Hermalin (2005), and Adams and Ferreira (forthcoming). The preferences of individual committee members can be aggregated so that a committee acts as if it were a single-player with a utility function that puts a positive weight $\beta$ on firm value and a negative weight on monitoring effort. The audit committee's utility function can thus be stated as

$$
U_{\text {audit }}=\beta V-c(e) \text {. }
$$

As in Hermalin (2005), $\beta$ is exogenously given and the result of all factors that determine how the board weights the costs and benefits of monitoring. The board's 
weight on firm value is expected to increase in the board's shareholding and long term interest in the firm, the concern for public opinion and reputation, and the degree to which the board is independent from the CEO.

The preferences of the compensation committee are more intricate. Through the formation of committees, board functions are separated. However, the specific extent to which functions are separated depends on the composition of the two committees. This follows because directors might sit on more than one committee and hence are responsible for more than one task. Compensation committee members who also serve on the audit committee will take into account that their choice of the pay-performance sensitivity of CEO compensation will affect their job at the audit committee (i.e., the optimal level of monitoring). In the case where tasks are not separated at all, because, for example, the two committees consist of exactly the same directors, then the preferences of the two committees coincide, i.e., $U_{\text {comp }}^{1}=U_{\text {audit }}$. On the other hand, if the two committees are two distinct entities, task separation is at its maximum, and the compensation committee's preferences are given by $U_{\text {comp }}^{0}=\beta V$. In this case, the compensation committee will ignore the cost of monitoring when setting CEO pay since it is not involved in the oversight function. The level of task separation on boards not only depends on the director overlap between the two committees, but more generally on the degree of interaction between the committees, e.g., how often the whole board meets or whether the chair of the compensation committee is also on the audit committee. We refer to the degree of interaction as committee interlock $\gamma \in[0,1]$. We define $\gamma$ as the extent to which the preferences of the audit committee enter the preferences of the compensation committee:

$$
U_{\text {comp }}^{\gamma}=\gamma U_{\text {comp }}^{1}+(1-\gamma) U_{c o m p}^{0}=\beta V-\gamma c(e),
$$

For a lower level of $\gamma$, the compensation committee cares less about the cost of mon- 
itoring, which characterizes a situation where task separation is higher.

\section{Results}

\subsection{Committee structure and decision making}

We first analyze the choice of activities in stage 3 . Since $a_{1}, a_{2}$, and $e$ are unobservable, we can assume without loss of generality that they are chosen simultaneously. The CEO's optimization problem is

$$
\max _{a_{1}, a_{2}} b\left(m_{1} a_{1}+m_{2}(1-e) a_{2}\right)-\frac{1}{2} a_{1}^{2}-\frac{1}{2} a_{2}^{2}
$$

taking $e$ as given. The audit committee's optimization problem is,

$$
\max _{e} \beta V-c(e)
$$

taking $a_{1}$ and $a_{2}$ as given. In equilibrium, each party correctly anticipates the other party's action, that is, $a_{1}, a_{2}$, and $e$ are best responses to each other.

Lemma 1 The equilibrium strategies $a_{1}, a_{2}$, and e are jointly determined by the following first-order conditions:

$$
\begin{gathered}
a_{1}=b m_{1}, \\
a_{2}=b m_{2}(1-e), \\
\beta\left[v_{2}+b m_{2}\right] a_{2}=c^{\prime}(e) .
\end{gathered}
$$

For a given level of monitoring, the CEO's incentive to exert productive effort and his incentive to engage in manipulation both increase with the pay-performance sensitivity $b$. Moreover, the CEO has a lower incentive to manipulate if the equilibrium 
level of monitoring is greater. This follows because greater monitoring reduces the productivity of $a_{2}$, making it less attractive to engage in manipulation.

Manipulation by the CEO is detrimental for the board because it directly destroys firm value (if $v_{2}>0$ ) and boosts CEO compensation. When deciding on the monitoring intensity, the audit committee puts a weight of $\beta$ on the benefit of monitoring. Since it has to bear the full cost of monitoring, it devotes too little attention to the oversight task.

Of particular interest is the total effect that a higher pay-performance sensitivity, $b$, has on the level of monitoring and on the CEO's action choices. Substituting (2) into (3) yields $\beta\left[v_{2}+b m_{2}\right]\left[b m_{2}\left(1-e^{*}\right)\right]-c^{\prime}\left(e^{*}\right)=0$. It is straightforward to verify that monitoring is increasing in $b$. Intuitively, when $b$ increases, monitoring becomes more important to the board since the CEO's bonus is larger and his direct incentive to manipulate stronger. While it is clear that a higher pay-performance sensitivity results in a larger effort $a_{1}$, the total effect on the manipulative act $a_{2}$ is ambiguous. On the one hand, a greater $b$ directly motivates the CEO to engage in more manipulation. On the other hand, it also improves the audit committee's monitoring incentive, which deters manipulation. Depending on which effect is stronger, the manipulative act either increases or decreases with $b$.

Lemma 2 As the pay-performance sensitivity $b$ increases, the monitoring effort $e^{*}$ and the productive act $a_{1}^{*}$ increase, while the manipulative act $a_{2}^{*}$ may increase or decrease.

In stage 2 , the compensation committee sets the pay $F$ and $b$ to maximize its utility. In our setting, the optimal fixed payment $F$ is always zero. The compensation 
committee's problem is

$$
\max _{b} \beta V-\gamma c(e)
$$

subject to (1), (2), and (3).

We show in the appendix that the compensation committee's optimal choice of $b$ satisfies

$$
\begin{aligned}
& {\left[v_{1} m_{1}-v_{2} m_{2}(1-e)^{2}\right]-\left[2 b m_{1}^{2}+2 m_{2}^{2}(1-e)^{2} b\right]} \\
& +\left[b m_{2}(1-e)\left(v_{2}+m_{2} b\right)(2-\gamma) \frac{d e}{d b}\right]=0,
\end{aligned}
$$

where $e$ is determined by (2) and (3).

In determining the optimal pay-performance sensitivity, the compensation committee takes into account the direct impact of $b$ on the CEO's choice of $a_{1}$ and $a_{2}$ (as expressed in the first term in square brackets) and on the CEO's compensation (as expressed in the second term in square brackets). The board also considers the positive effect of $b$ on the level of monitoring (as expressed in the last term in square brackets). This last effect is intuitive for $\gamma=0$. In this case, the two committees are distinct groups so that the compensation committee will push the audit committee's incentive to monitor by choosing a larger $b$. This effect also occurs-but to a lower extent-when the whole board is responsible for both tasks, i.e., when $\gamma=1$. In this case, the pay-performance sensitivity of CEO compensation serves as a substitute for commitment. To see this, suppose that the board was able to commit to a certain level of monitoring prior to the CEO's action choices. The board would then choose a monitoring intensity greater than the one implied by Lemma 1 . This would be beneficial because the anticipation of diligent monitoring reduces the CEO's incentive to take manipulative actions. Due to the lack of commitment, however, the board will instead enhance the pay-performance sensitivity $b$. By doing so, the board increases 
its own incentive to engage in monitoring in stage 3 , which credibly communicates to the CEO that it will take its oversight function seriously.

Condition (5) leads to our first proposition.

Proposition 1 As committees become less interlocked, the pay-performance sensitivity, $b$, increases.

The extent to which the compensation committee considers the positive effect of $b$ on $e$ depends on the degree of committee interlock. For $\gamma=1$, directors who design the CEO incentive contract also have to perform the oversight function. Hence, when choosing $b$, they take into account the cost of subsequent monitoring. If the committee interlock decreases, the compensation committee is less involved in monitoring and hence less concerned about the cost of monitoring. As a consequence, it will increase the pay-performance sensitivity of CEO compensation to further boost the oversight effort. This explains Proposition 1.

The next corollary follows directly from Lemma 2 and Proposition 1.

Corollary 1 As committees become less interlocked, the monitoring effort $e^{*}$ and the productive act $a_{1}^{*}$ increase, while the manipulative act $a_{2}^{*}$ may increase or decrease.

Another important question is how the committee structure affects the expected magnitude of earnings management, which is defined by $E M \equiv m_{2}(1-e) a_{2}$. The answer to this question is not clear cut. Less interlocked committee structures (lower $\gamma$ ) lead to executive compensation schemes that are more performance sensitive. This increases the audit committee's attention devoted to monitoring and hence reduces the magnitude of earnings management EM. However, as described in Lemma 2, the effect of a larger $b$ on $a_{2}$ is ambiguous. For this reason, $E M$ can be either increasing or decreasing in $b$, with $d E M / d b=c^{\prime \prime}(e)-\beta b m_{2} v_{2}-3 b^{2} \beta m_{2}^{2}$. 
We obtain an unambiguous link if we make some additional assumptions. Assume that $c^{\prime \prime}(e)$ is a constant, e.g., $c$, and let $\beta^{t}$ be the level of $\beta$ that satisfies $\beta b(0) m_{2} v_{2}+$ $3[b(0)]^{2} \beta m_{2}^{2}=c$, where $b(0)$ is the $b$ that maximizes (5) for $\gamma=0$.

Proposition 2 For $\beta<\beta^{t}$, the level of earnings management increases when committees become less interlocked, $\frac{d E M}{d \gamma}<0$.

When directors' stake in the firm, $\beta$, is low, the attention devoted to monitoring is low as well. As a consequence, the CEO's expected marginal benefit of manipulation increases strongly when $b$ increases. This effect outweighs the effect that an increase in $e$ has on $E M$, resulting in a net increase in $E M$.

\subsection{The optimal board structure}

Shareholder-value maximization. We are now able to determine the level of committee interlock $\gamma$ that is optimal for shareholders. Of course, in our setting, the allocation of board members to committees is irrelevant in a first-best world. Therefore, the level of interlock $\gamma$ is also irrelevant. In a second-best world, however, $\gamma$ affects CEO pay, board monitoring, and the productive and manipulative act.

In stage 1 , shareholders choose the structure of the board, $\gamma$, that maximizes firm value $V$.

Proposition 3 The committee interlock that maximizes firm value is $\gamma=0$.

Proposition 3 is proven in the appendix.

Recall that the compensation committee's optimal choice of $b$ in stage 2 maximizes

$$
\beta V-\gamma c(e) .
$$


If committees are interlocked, i.e., $\gamma>0$, the compensation committee will take into account the effect the choice of $b$ has on the cost of monitoring. Since linking CEO pay closely to performance increases the need for subsequent monitoring, the compensation committee will find it beneficial to choose a pay-performance sensitivity that is too low from the perspective of shareholders. For $\gamma=0$, the interests of the compensation committee are aligned with those of shareholders, resulting in the optimal choice of $b$.

Of course, the optimal committee structure does not minimize earnings management, EM. Shareholders are willing to accept potential increases in earnings management that go along with stronger pay-performance sensitivities, since greater incentives also induce the CEO to work harder on the productive task.

It is worth noting that the utility of the directors is always positive in our setting, regardless of the level of $\gamma$. Consider a board without committees that has to perform both functions. Directors could always choose to live a quite life and fulfill the minimum oversight level, i.e., $e=0$, at zero costs. In this case, the board's participation constraint is trivially satisfied. Indeed, in our setting, board members have a personal incentive to choose a higher level of oversight because they care about firm value. An important feature of our setting is that the board's optimal oversight level is increasing in the pay-performance sensitivity of the CEO's compensation contract. The board takes this effect into consideration when setting CEO pay. The question is how the equilibrium choice of CEO pay and oversight can be improved. As our model shows, one way to achieve this is to separate directors into two different committees. Choosing a subgroup of board members that does not participate in the oversight function and assigning this group the responsibility of setting CEO pay, increases the chosen pay-performance sensitivity of CEO compensation. For the members of the 
audit committee it is now privately optimal to choose a higher level of oversight. The combination of a higher pay-performance sensitivity and a higher oversight level is optimal for shareholders.

CEO's interest. In some firms it might be reasonable to assume that the CEO has the power to design the organization of the board. It is therefore interesting to take a look at the committee structure, $\gamma$, that is optimal for the CEO.

Proposition 4 The CEO's utility, $b M-c\left(a_{1}\right)-c\left(a_{2}\right)$, is maximized for $\gamma=0$.

The proof of Proposition 4 is in the appendix.

When the two committees become less interlocked, both the pay-performance sensitivity $b$ and the level of monitoring $e$ increase. The first effect clearly benefits the CEO while the second effect hurts him. However, as shown in the appendix, the first effect dominates the second, leaving the CEO better off with less interlocked committee structures.

Other factors that influence the level of $\gamma$. Of course, in practice we do not always observe that the audit committee and the compensation committee are two distinct groups (i.e., $\gamma=0$ ). There are several reasons that can explain the existence of committee interlock. For example, the firm may decide to limit the size of the board to save compensation costs, reduce free-rider problems or due to lack of talent. In addition, new regulatory standards require a certain number of directors to be independent from management and financially literate. This restricts the degree of committee interlock that can be achieved in boards. Moreover, our model ignores potential benefits of communication between board members that perform different 
functions. The benefits of information sharing between committees may provide a counterweight to the effects we have outlined in this study.

Another, less obvious reason for why shareholders may benefit from interlocked committees emerges from a lack of independence of the board from management. We devote the next section to the discussion of how board dependence affects the optimal choice of committee interlock.

\subsection{Dependent boards}

In recent years, boards of directors have been criticized for serving the interests of CEOs rather than those of shareholders. Directors are said to be inclined to favor executives because executives have some control over director compensation and over the re-nomination process (see, e.g., Bebchuk and Fried (2004)). We are therefore interested in the question how the board's dependence on the CEO affects the optimal level of committee interlock. A natural way to model dependence is to assume that a dependent board benefits from being friendly to the CEO. We therefore assume in this section that the board's utility is an increasing function of the CEO's utility. The compensation and the audit committees' utilities are then given by $\beta V-c(e)+\delta U_{C E O}$ and $\beta V-\gamma c(e)+\delta U_{C E O}$, respectively. The weight directors place on the CEO's utility, $\delta$, is interpreted as the board's degree of dependence. We assume $\beta>\delta$ so that it is not optimal for the board to make unbounded monetary transfers from the firm to the CEO. This assumption also implies that it is not optimal to make fixed transfers from the firm to the $\mathrm{CEO}$, i.e., $F=0$ remains optimal.

We know from the previous section that if the board is independent, $\delta=0$, the board structure that maximizes firm value is $\gamma=0$. This result no longer holds if the board is dependent on the CEO. 
Proposition 5 When the board is dependent on the CEO $(\delta>0)$, firm value is maximized for $\gamma>0$. The CEO's utility is maximized for $\gamma=0$.

The proof is in the appendix.

When the board is dependent on the CEO, firm value is maximized if there is some committee interlock. Without committee interlock $(\gamma=0)$, a dependent board is inclined to offer the CEO a bonus coefficient $b$ that is excessive from the perspective of shareholders. The reason is that a dependent board is not only concerned about firm value, but also wishes to be friendly to the CEO. Committee interlock creates countervailing incentives as the compensation committee now also weights the monitoring cost when choosing $b$. This is akin to imposing an additional cost of being friendly to the CEO. The level of interlock that is optimal for shareholders is the level that induces the compensation committee to choose the pay-performance sensitivity that maximizes firm value. However, note that even when the committee structure is chosen optimally for shareholders, board dependence is nevertheless detrimental to shareholders, as it leads to a reduced monitoring effort.

\section{Empirical Implications}

The academic literature has identified and analyzed governance factors that are expected to influence the quality of the internal control process in corporations. Popular governance indicators are, for instance, the size of boards or committees, directors' degree of independence from the CEO, their stock ownership, and whether the CEO is also the chairman of the board (Weisbach (1988), Jensen (1993), Yermack (1996), Core, Holthausen, and Larcker (1999)).

Our paper contributes to this literature by carving out another channel through 
which board structure has an impact. We focus on task separation on boards, which is arguably an important consequence of forming committees. The model provides predictions relating the board structure to board decision making and organizational performance. What matters for our predictions is the degree of committee interlock on boards, $\gamma$. A straightforward way to measure this interlock in corporations is to look at the extent to which boards have adopted committees. Generally, boards with committees are expected to be less interlocked, i.e., employ a greater degree of task separation, than boards without committees. For those firms that are required to have board committees by regulation, possible proxies for interlock are, e.g., whether or not the chairman of the compensation committee also sits on the audit committee or the fraction of compensation committee members who also serve on the audit committee.

For the purpose of illustration, it is interesting to take a look at the degree of interlock in the 30 corporations comprising the Dow Jones Industrial Average. A review of the 2005 proxy statements reveals that the size of the compensation committee ranges from three to seven members, and the members of the compensation committee, on average, sit on 1.47 other committees. However, for 12 corporations no member of the compensation committee also sits on the audit committee, and for ten corporations only one member sits on both committees. For only seven corporations, the chairman of the compensation committee also serves on the audit committee. Thus, for most firms, the degree of interlock between the compensation committee and the audit committee is relatively small. This suggests that the introduction of committees indeed results in a separation of the two functions of setting CEO compensation and monitoring. 
Board structure and CEO compensation. Our analysis indicates a link between the structure of the board and CEO incentive pay. In particular, the model predicts that a reduction in the degree of committee interlock leads to a greater payperformance sensitivity of CEO compensation. We are not aware of any existing empirical research that examines this relation.

CEO compensation and earnings management. Policymakers and regulators have devoted special attention to determining the cause of recent accounting scandals. Many have argued that the increased use of equity incentive pay like stock and stock options provided executives with excessive incentives to artificially inflate reported earnings (see Erickson, Hanlon, and Maydew (2006) for a discussion). Our model shows that the relation between CEO incentives and earnings management is less obvious than it appears at first sight. The reason is that an increase in the payperformance sensitivity, $b$, not only has a positive effect on the CEO's direct incentive to engage in manipulation, but also on the audit committee's incentive to diligently oversee the accounting process. Hence, the magnitude of earnings management, $E M$, can increase or decrease with $b$, depending on which effect is stronger. This might explain why Erickson, Hanlon, and Maydew (2006) find no consistent evidence of a link between the pay-performance sensitivity of executive compensation contracts and accounting fraud. ${ }^{1}$

We only obtain an unambiguous negative link when the audit committee's monitoring incentive is low, i.e., if $\beta<\beta^{t}$. However, even in this case, a positive relation

\footnotetext{
${ }^{1}$ However, there are other papers that provide some evidence on a positive relation between the level of stock-based and in particular option-based compensation and the degree of earnings management (see, e.g., Bergstresser and Philippon (forthcoming), Burns and Kedia (2004), Peng and Röell (2004)).
} 
between the pay-performance sensitivity and the level of earnings management is not a conclusive indication of the desirability of performance insensitive compensation schemes. Shareholders are willing to accept the earnings management that goes along with increased CEO incentives as long as the benefit of higher incentives outweighs the cost of earnings management.

Board structure and oversight. Our model predicts that a reduction in the degree of committee interlock leads to better oversight of the financial reporting process. The link between board structure and monitoring is, however, indirect. A lower committee interlock results in a greater pay-performance sensitivity of CEO compensation, which, in turn, enhances the audit committee's incentive to carefully oversee the reporting process.

There are no papers that directly test our prediction, as the level of board oversight is hard to measure. However, there is a large body of empirical research that examines the relation between board structure and earnings management. Our model suggests that it is important to control for the pay-performance sensitivity when analyzing this link. Without such a control variable, it is difficult to interpret the empirical findings, as a lower magnitude of earnings management can be the result of better monitoring or the use of compensation systems that are less performance sensitive. To elaborate on this issue, consider a study that finds no relation between the presence of audit committees and the level of earnings management. One might be tempted to conclude that audit committees do not play an important role in the corporate governance process. However, as our model shows, this might be the wrong conclusion. If one accepts the assumption that the formation of committees leads to an increase in task separation, our model predicts that the presence of audit committees positively 
affects the pay-performance sensitivity of CEO compensation. This, in turn, changes both the CEO's direct incentive to manipulate and the level of board oversight. The two effects work in opposite directions, implying that (on average) the magnitude of earnings management may not change. This does not indicate, however, that the adoption of audit committees has no effect on corporate governance: the move toward more performance sensitive pay systems (that is triggered by greater task separation) also enhances the CEO's incentive to work hard on the productive tasks, which results in an increase in firm value.

The empirical literature that analyzes whether the existence of audit committees influences the quality of the financial reporting process produces mixed evidence. While Dechow, Sloan, and Sweeney (1996) and Beasley et al. (2000) find a positive association between audit committee presence and financial reporting quality, Beasley (1996) and Peasnell, Pope, and Young (2005) find no such relation.

\section{Conclusion}

Arguably, two of the most important board functions are setting CEO pay and overseeing the financial reporting process. Different committees are responsible for performing these functions, yet both functions are very much related. Accounting-based compensation schemes encourage the CEO to manipulate earnings, which, in turn, makes it necessary for the board to diligently perform the oversight role. Put differently, CEO pay and the level of monitoring are substitutes in reducing earnings management. Audit committee members who are responsible for overseeing the reporting process will favour a lower pay-performance sensitivity of CEO compensation than board members who are not involved in the oversight process. Our analy- 
sis provides testable predictions concerning the relations between board committee structure, CEO compensation, board oversight and earnings management.

Important incentives for board members to act as overseers of the financial reporting process also stem from their fiduciary duty and potential liability claims (Gutierrez (2003)). We do not consider claims against directors in our model. However, our qualitative results continue to hold when directors face legal penalties. The Sarbanes Oxley Act of 2002 assigns directors serving on the audit committee a special responsibility for overseeing the firm's financial accounting process. Hence, when committee interlock is reduced, the compensation committee will care less about potential legal sanctions. This again implies that a lower committee interlock will lead to a stronger pay-performance sensitivity of CEO compensation, which, in turn, will increase the audit committee's incentive to carefully oversee the reporting process.

\section{Appendix}

\section{Proof of Equation (5).}

Substituting (1), (2) and $M=m_{1} a_{1}+m_{2}(1-e) a_{2}$ into (4) yields

$$
\beta\left(b v_{1} m_{1}-b v_{2} m_{2}(1-e)^{2}-b^{2} m_{1}^{2}-m_{2}^{2}(1-e)^{2} b^{2}\right)-\gamma c(e) .
$$

The first derivative with respect to $b$ is

$$
\begin{aligned}
& \beta\left(v_{1} m_{1}-2 b m_{1}^{2}-m_{2}(1-e)^{2}\left(v_{2}+2 m_{2} b\right)\right) \\
& +\beta\left(2 b m_{2}(1-e)\left(v_{2}+m_{2} b\right)-\frac{\gamma}{\beta} c^{\prime}(e)\right) \frac{d e}{d b}=0 .
\end{aligned}
$$

(Note that $e$ is a function of $b$.) Inserting (2) into (3) and substituting this into (6) gives (5). 


\section{Proof of Proposition 3.}

Let $b^{V}$ denote the level of $b$ that maximizes firm value, $V$. To determine $b^{V}$ we solve the following problem: maximize $v_{1} a_{1}-v_{2}(1-e) a_{2}-b M$ subject to (1), (2), and (3). Similar to the proof of equation (5), it can be shown that $b^{V}$ satisfies

$$
\begin{aligned}
& v_{1} m_{1}-v_{2} m_{2}(1-e)^{2}-2 b m_{1}^{2}-2 m_{2}^{2}(1-e)^{2} b \\
& +\left(2 b m_{2}(1-e)\left(v_{2}+m_{2} b\right)\right) \frac{d e}{d b}=0 .
\end{aligned}
$$

Comparing (7) with (5) shows that the compensation committee will choose the desired pay-performance sensitivity $b=b^{V}$, if $\gamma=0$.

\section{Proof of Proposition 4.}

The utility of the CEO is $b\left(m_{1} a_{1}+m_{2}(1-e) a_{2}\right)-0.5 a_{1}^{2}-0.5 a_{2}^{2}$. Substituting (1) and (2) into this equation yields $0.5 b^{2} m_{1}^{2}+0.5 b^{2} m_{2}^{2}(1-e(b))^{2}$. The first derivative with respect to $b$ is

$$
b m_{1}^{2}+b m_{2}^{2}(1-e)^{2}-b^{2} m_{2}^{2}(1-e) \frac{d e}{d b},
$$

with $\frac{d e}{d b}=\frac{\beta m_{2}(1-e)\left(v_{2}+2 m_{2} b\right)}{\beta b m_{2}\left(v_{2}+m_{2} b\right)+c^{\prime \prime}(e)}>0$. It is straightforward to show that (8) is always positive for $m_{1} \geq m_{2}$ (which we have assumed) implying that the CEO is better off when $b$ increases.

\section{Proof of Proposition 5.}

When the board is dependent on the CEO, the audit committee's optimization problem is,

$$
\begin{aligned}
& \max _{e} \beta\left[v_{1} a_{1}-v_{2}(1-e) a_{2}-b\left(m_{1} a_{1}+m_{2}(1-e) a_{2}\right)\right]-c(e) \\
& +\delta\left[b\left(m_{1} a_{1}+m_{2}(1-e) a_{2}\right)-\frac{1}{2} a_{1}^{2}-\frac{1}{2} a_{2}^{2}\right]
\end{aligned}
$$

taking $a_{1}$ and $a_{2}$ as given. The optimal monitoring effort satisfies

$$
\beta\left[v_{2} a_{2}+b m_{2} a_{2}\right]-c^{\prime}(e)-\delta\left[b m_{2} a_{2}\right]=0 .
$$


Substituting (1) and (2) into (9) yields:

$$
\beta b m_{2}(1-e)\left(v_{2}+b m_{2}\right)-c^{\prime}(e)-\delta b^{2} m_{2}^{2}(1-e)=0 .
$$

The level of $b$ that maximizes firm value, denoted $b_{d e p}^{V}$, must satisfy (7) with $\frac{d e}{d b}=\frac{\beta(1-e)\left(v_{2} m_{2}+2 b m_{2}^{2}\right)-\delta 2 b m_{2}^{2}(1-e)}{\beta b m_{2}\left(v_{2}+b m_{2}\right)+c^{\prime \prime}(e)-\delta b^{2} m_{2}^{2}}$ and $e$ satisfying (10).

The compensation committee chooses the level of $b$ that maximizes

$$
\max _{b} \beta\left(v_{1} a_{1}-v_{2}(1-e) a_{2}-b M\right)-\gamma c(e)+\delta\left[b M-\frac{1}{2} a_{1}^{2}-\frac{1}{2} a_{2}^{2}\right],
$$

subject to (1), (2), and (10). Similar to the proof of equation (5), it can be shown that the compensation committee's choice of $b$ satisfies

$$
\begin{aligned}
& \left(v_{1} m_{1}-2 b m_{1}^{2}-m_{2}(1-e)^{2}\left(v_{2}+2 m_{2} b\right)\right) \\
& +\left(2 b m_{2}(1-e)\left(v_{2}+m_{2} b\right)-\frac{\gamma}{\beta}\left(\beta b m_{2}(1-e)\left(v_{2}+b m_{2}\right)-\delta b^{2} m_{2}^{2}(1-e)\right)\right) \frac{d e}{d b} \\
& +\frac{\delta}{\beta}\left[m_{1}^{2} b+m_{2}^{2}(1-e)^{2} b-m_{2}^{2}(1-e) b^{2} \frac{d e}{d b}\right]=0 .
\end{aligned}
$$

with $\frac{d e}{d b}=\frac{\beta(1-e)\left(v_{2} m_{2}+2 b m_{2}^{2}\right)-\delta 2 b m_{2}^{2}(1-e)}{\beta b m_{2}\left(v_{2}+b m_{2}\right)+c^{\prime \prime}(e)-\delta b^{2} m_{2}^{2}}$ and $e$ satisfying (10).

It is straightforward to show that the last term in square brackets is positive given $m_{1} \geq m_{2}$. Hence, in order to induce the compensation committee to choose the desired pay-performance sensitivity $b=b_{d e p}^{V}$, it must be that $\gamma>0$.

\section{References}

[1] Adams, R. B., 2003, What do Boards do? Evidence from Board Committee and Director Compensation Data, Working Paper.

[2] Adams, R. B., and D. Ferreira, forthcoming, A Theory of Friendly Boards, Journal of Finance. 
[3] Almazan, A., and J. Suarez, 2003, Entrenchment and Severance Pay in Optimal Governance Structures, Journal of Finance 58, 519-547.

[4] Beasley, M. S., 1996, An Empirical Analysis of the Relation Between the Board of Director Composition and Financial Statement Fraud, The Accounting Review $71,443-465$.

[5] Beasley, M. S., J. V. Carcello, D. R. Hermanson, and P. D. Lapides, 2000, Fraudulent Financial Reporting: Consideration of Industry Traits and Corporate Governance Mechanisms, Accounting Horizons 14, 441-454.

[6] Bebchuk, L. A., and J. M. Fried, 2004, Pay without Performance. The Unfilled Promise of Executive Compensation, Harvard University Press, Cambridge.

[7] Bergstresser, D., and T. Philippon, forthcoming, CEO Incentives and Earnings Management, Journal of Financial Economics.

[8] Burns, N., and S. Kedia, 2004, The Impact of Performance-Based Compensation on Misreporting, Working Paper.

[9] Collins, D. W., and P. Hribar, 2000, Earnings-Based and Accrual-Based Market Anomalies: One Effect or Two?, Journal of Accounting and Economics 29, 101123.

[10] Core, J. E., R. W. Holthausen, and D. F. Larcker, 1999, Corporate Governance, Chief Executive Officer Compensation, and Firm Performance, Journal of Financial Economics 51, 371-406.

[11] Dutta, S., and F. Gigler, 2002, The Effect of Earnings Forecasts on Earnings Management, Journal of Accounting Research 40, 631-655. 
[12] Dechow, P. M., R. G. Sloan, and A. P. Sweeney, 1996, Causes and Consequences of Earnings Manipulation: An Analysis of Firms Subject to Enforcement Actions by the SEC, Contemporary Accounting Research 13, 1-36.

[13] Erickson, M., M. Hanlon, and E. L. Maydew, 2006, Is There a Link Between Executive Equity Incentives and Accounting Fraud?, Journal of Accounting Research 44, 113-143.

[14] Ewert, R., and A. Wagenhofer, 2005, Economic Effects of Tightening Accounting Standards to Restrict Earnings Management, The Accounting Review 80, 11011124.

[15] Farber, D. B., 2005, Restoring Trust After Fraud: Does Corporate Governance Matter? The Accounting Review 80, 539-561.

[16] Feltham, G. A., and J. Xie, 1994, Performance Measure Congruity and Diversity in Multi-Task Principal/Agent Relations, The Accounting Review 69, 429-453.

[17] Fischer, P. E., R. E. Verrecchia, 2000, Reporting Bias, The Accounting Review $75,229-245$.

[18] Gutierrez, M., 2003, An Economic Analysis of Corporate Directors' Fiduciary Duties, RAND Journal of Economics 34, 516-535.

[19] Hermalin, B. E., 2005, Trends in Corporate Governance, Journal of Finance 60, $2351-2384$.

[20] Hermalin, B. E., and M. S. Weisbach, 1998, Endogenously Chosen Boards of Directors and Their Monitoring of the CEO, American Economic Review 88, 96-118. 
[21] Hermalin, B. E., and M. S. Weisbach, 2003, Boards of Directors as an Endogenously Determined Institution: A Survey of the Economics Literature, Economic Policy Review 9, 7-26.

[22] Jensen, M., 1993, The Modern Industrial Revolution, Exit, and the Failure of Internal Control Systems, Journal of Finance 48, 831-880.

[23] Klein, A., 2002, Audit Committee, Board of Director Characteristics, and Earnings Management, Journal of Accounting and Economics 33, 375-400.

[24] Larcker, D. F., S. A. Richardson, I. Tuna, 2005, How Important is Corporate Governance? Working Paper, Wharton School.

[25] Lorsch, J., and E. MacIver, 1989, Pawns or Potentates, Harvard Business School Press, Boston.

[26] Peasnell, K. V., P. F. Pope and S. Young, 2005, Board Monitoring and Earnings Management: Do Outside Directors Influence Abnormal Accruals? Journal of Business Finance \& Accounting 32, 1311-1346.

[27] Peng, L., and A. Röell, 2004, Executive Pay, Earnings Manipulation, and Shareholder Litigation, Working Paper.

[28] Sloan, R. G., 1996, Do Stock Prices Fully Reflect Information in Accruals and Cash Flows About Future Earnings?, The Accounting Review 71, 289-315.

[29] Weisbach, M. S., 1988, Outside Directors and CEO Turnover, Journal of Financial Economics 20, 431-460.

[30] Yermack, D., 1996, Higher Market Valuation for Firms with a Small Board of Directors, Journal of Financial Economics 40, 185-211. 